\title{
PATRIMONIAL FAMILIAR. RETOS Y OPORTUNIDADES
}

\author{
FAMILY PATRIMONIAL. CHALLENGES AND OPPORTUNITIES
}

\author{
Liliana del Carmen Alvarado-Avendaño ${ }^{1} *$ iD. \\ 1. Escuela Judicial del Estado de Tabasco, México. aa_liliana@hotmail.com \\ * Autor de correspondencia: Liliana del Carmen Alvarado-Avendaño, correo electrónico: aa_liliana@hotmail.com
}

\section{RESUMEN}

El Patrimonio Familiar es descrito como el conjunto de obligaciones y derechos que, constituyendo una unidad jurídica y económica, destinada a la satisfacción de los deberes derechos de contenido pecuniario, derivados de la convivencia familiar $\mathrm{y}$, en su caso, a garantizar el cumplimiento de éstos, independientemente de la causa generadora del beneficiario grupo social primario, que bien puede ser el matrimonio, el concubinato, la procreación o la adopción. En consecuencia, varía su naturaleza jurídica, adquiriendo las características propias de lo que la doctrina moderna denomina patrimonio afectación, ampliándose, por ende, la oportunidad de destinar otro tipo de bienes al fin que nos ocupe, superando así la tradicional posibilidad de afectar únicamente la casa habitación y una parcela cultivable, debiéndose incluir todo tipo de derechos y bienes valorables en dinero o susceptibles de este tipo de valoración.

Palabras clave: Derecho civil; familia; patrimonio; protección integral.

Cómo citar:

Alvarado-Avendaño, Liliana del Carmen. (2021). Patrimonial familiar. Retos y oportunidades. Revista de Investigaciones Universidad del Quindio, 33(S2), 219-226. https://doi.org/10.33975/riuq.vol33nS2.454 


\begin{abstract}
Family Assets must be defined as the set of rights and obligations that, constituting a legal and economic unit, destined to the satisfaction of the rights of pecuniary content, derived from family coexistence and, where appropriate, to guarantee compliance with These, regardless of the generating cause of the beneficiary primary social group, which may well be marriage, cohabitation, procreation or adoption. Consequently, its legal nature varies, acquiring the characteristics of what modern doctrine calls patrimony affectation, thus expanding the opportunity to allocate other types of assets to the purpose at hand, thus overcoming the traditional possibility of only affecting the house and a cultivable parcel, all types of rights and assets that can be valued in money or susceptible to this type of valuation must be included.
\end{abstract}

Keywords: Civil law; family; heritage; comprehensive protection.

\title{
INTRODUCCIÓN
}

La familia es el núcleo social sobre el que reposa la estructura de las diversas sociedades actuales, el ser humano nace integrado a una familia, siendo que mediante esta el hombre realiza su desarrollo, la influencia de la familia y de su núcleo se extiende en el tiempo del ser humano en interacción social, de tal manera que esta integración es una necesidad natural, en la que el hombre no podría perdurar sin ese soporte.

Derivado de la complejidad de su estado y estructura el significado de familia es objeto de estudio y análisis desde múltiples disciplinas. Incluso, dada la etimología de la palabra, por la economía. Deviene por ello importante el encaminar elementos para proteger y resguardar su seguridad personal, patrimonial y familiar.

El espíritu de las leyes es vigilar por la seguridad de la sociedad, de ella emanan un buen funcionamiento eficaz y eficiente de la administración de justicia, procurando los diversos contextos sociales como el familiar. Por ello, las instituciones jurídicas atienden y afianzan mediante el acceso a la justicia como derecho humano mecanismos autocompositivo y heterocompositivo.

La protección de la institución familiar constituye una característica que, desde muy antiguo, ha merecido la atención de los poderes públicos en la práctica totalidad de los ordenamientos jurídicos. Posteriormente, en unos países, el proceso de constitucionalización de la familia se reflejó clara y directamente en las Constituciones del siglo XX; en otros países, las normas se han inspirado, entre otras fuentes posibles, en principios constitucionales, convenios y tratados internacionales.

\section{METODOLOGÍA}

Para el desarrollo de este documento se empleó un enfoque cualitativo con alcance documental, descriptivo y analítico. Fue producto de un método de naturaleza jurídica basado en la hermenéutica de las fuentes del Derecho, aplicada al objeto de estudio. Desde el método axiológico el espíritu de las leyes es velar por la seguridad de la sociedad, ya que de ella depende el correcto funcionamiento de formas de solidaridad humana y es la principal guiadora y creadora de nuestros quehaceres humanos, 
teniendo como objetivo proteger todos los ámbitos que rodean a la familia, creando las instituciones jurídicas necesarias.

\section{RESULTADO}

\section{Protección amplia a la familia y su interés}

Entre las formulaciones posibles encaminadas a la protección patrimonial familiar, una de ellas, consiste en evitar que determinados bienes ligados por sus especiales características al bienestar familiar (Lepin, 2014), puedan ser objeto de agresión como consecuencia de actuaciones, contractuales o no, del propietario de los bienes. Esta protección no se formula como privilegio que podría ser contrario a otros principios constitucionales o intereses dignos de protección, sino que se instaura como una especial protección legislada en favor de la dignidad de la persona y de la familia a la que se atribuye el carácter de célula básica de la sociedad.

"E1 Estado debe otorgar los beneficios de la seguridad social, que tendrá carácter de integral e irrenunciable, en especial, la ley establece el seguro social obligatorio, que está a cargo de entidades nacionales o estatales con autonomía financiera y económica, administradas por los interesados con participación del Estado, sin que pueda existir superposición de aportes; jubilaciones y pensiones móviles; la protección integral de la familia; la defensa del patrimonio o bien de familia; la compensación económica familiar y el acceso a una vivienda digna." (Machado, Cedeño \& Fuentes, 2019).

La referencia constitucional a la protección integral de la familia, conlleva la promoción de la familia a la jerarquía y dignidad de la sociedad primaria y núcleo fundamental, para lo cual la ampara, garantiza y robustece en forma plena: material y moral. A su vez, la defensa del Patrimonio Familiar complementa la dicción anterior, ya que con ello se pretende la protección patrimonial de la casahabitación destinada a vivienda, tomando la residencia familiar como centro vertebrador de la vida del grupo, propiciando la unidad y estabilidad familiar, y favoreciendo el acceso y mantenimiento de una vivienda digna y decorosa. En relación con dichos principios, tanto la doctrina como la jurisprudencia, se apoyan en la jerarquía o rango constitucional de la política legislativa sobre el Patrimonio Familiar y lo referente al bien de familia se haya comprometido el orden público.

En su plasmación positiva y con el fin de proteger al grupo familiar de las crisis y vicisitudes económicas que pueden conllevar la pérdida de la vivienda o la explotación familiar (Armijo, 2016), el derecho promueve la protección patrimonial de la vivienda urbana o rural.

Este es un principio supremo que recoge con toda precisión la Carta Magna del país en su Artículo 4": "El varón y la mujer son iguales ante la ley. Esta protegerá la organización y el desarrollo de la familia" y en su Sexto Párrafo instruye: "Toda familia tiene derecho a disfrutar de vivienda digna y decorosa. La Ley establecerá los instrumentos y apoyos necesarios a fin de alcanzar tal objetivo" (Diario Oficial de la Federación, 2017)

El Patrimonio Familiar es una institución encaminada a resguardar la casa de habitación, el Estado asume interés en que la familia proteja y asegure un espacio de infraestructura en el cual residir (Galván, 1996). En ese sentido, la vivienda digna como derecho humano es fundamental para el patrimonio familiar. 
Con el Patrimonio Familiar se protege un inmueble como patrimonio de una familia determinada (Rojina, 2004), considerándose inembargable. En el sentido de salvaguardar y proteger el patrimonio familiar de cualquier pretensión económica acuñada por terceros.

Además de esta protección específica a un inmueble, con la figura del Patrimonio Familiar se busca dotar a la familia y a sus miembros de un medio de sustento que no falle, de tal manera que las premuras de carácter económicas no afecten su normal y cabal desenvolvimiento (Borja, 2013). Por ello, se afecta tal inmueble con una finalidad u objetivo definido.

\section{El patrimonio familiar}

El origen de la palabra patrimonio deriva del término latino "Patrimonium" y significa: "hacienda que una persona ha heredado de sus ascendientes o bien los bienes propios que se adquieren por cualquier título" (Gutiérrez, 1999).

En un criterio jurídico, el patrimonio es un conjunto de ejercicio de poder y deber monetario que posee una persona. "Se habilita la expresión poderes y deberes en razón de que no solo los derechos subjetivos y las obligaciones pueden ser estimadas en dinero, sino también lo son las facultades, las cargas y en algunos casos el ejercicio de la potestad que se traduce en un valor pecuniario" (Instituto de Investigaciones Jurídicas, 2001).

Las características definitorias del patrimonio son las siguientes:

a. Contenido. Se halla integrado por elementos susceptibles de valoración económica, tanto positiva (activo), como negativa (pasivo). Quedan fuera, pues, los bienes de la personalidad y lo concerniente al Estado civil de la persona.

b. Estructura. Se distingue en él una esfera externa, pues cada patrimonio puede considerarse como independiente de los demás, en el sentido de que el ingreso o la salida de cada uno de sus elementos requiere un título, una causa que justifique ese paso, y una esfera interna, constituida por el ámbito de libertad que tiene el titular del patrimonio para gozar, tener y disfrutar sus bienes conforme a su naturaleza y al contenido de derechos y facultades sobre los mismos, esfera que queda jurídicamente neutralizada al no poder existir derechos subjetivos entre los bienes del mismo patrimonio.

c. Identidad. El patrimonio es considerado como una unidad, y como idéntico a través del tiempo, con independencia de los elementos que lo integren y de los avatares que les acaezcan, lo que constituye la base de los principios de responsabilidad patrimonial universal y de subrogación real.

d. Ex lege. La creación, transmisión, separación, reunión y disolución de patrimonios, abstracta y unitariamente considerados, están excluidas de la autonomía de la voluntad y sometidas a una regulación imperativa de las leyes.

El patrimonio es una universalidad de bienes, denominándose así toda pluralidad a los que es posible tratar unitariamente, como un todo. El patrimonio general está formado por la masa de bienes de que dispone el titular para obtener cualesquiera fines que se proponga; los patrimonios especiales son, como define Aloys Ritter Von Brinz, "bienes afectados a un fin” determinado. Esto explica que la persona tenga un solo patrimonio general y pueda, en cambio, tener varios patrimonios especiales. 
Siguiendo la distinción de los tipos de patrimonio que manufacturó De Castro y Bravo (2008), el Patrimonio de la Familia vendría a ser un Patrimonio separado, ya que se entiende como una masa patrimonial que pertenece a un patrimonio personal, pero del que se halla independizada por estar igualmente destinada a un fin específico. Precisamente en función de la naturaleza de este fin la creación de patrimonios separados está fuera del poder de la autonomía de la voluntad; a la vez encuadra en la distinción de ser un Patrimonio afectado a un fin y tienen un carácter excepcional.

El Patrimonio Familiar es una institución jurídica, dotada de fundamentos, caracteres y fines específicos. Se basa en la voluntad de los titulares del dominio para someter el inmueble que es objeto de alojamiento o sustento económico de la familia a un régimen especial. El beneficio principal que ofrece este régimen legal es la protección del inmueble que tiene por objeto asegurar la conservación dentro del patrimonio familiar, del inmueble que sirve como vivienda o explotación personal para sustento económico, para así procurar la cohesión familiar.

Es el conjunto de bienes constituido por resolución judicial y en forma única que aseguran y garantizan la subsistencia y bienestar de la familia (valor que debe sea reorientado), la cual, con el cumplimiento de los requisitos previstos en la normativa legal y entre otros efectos jurídicos, adquiere el carácter de bien inembargable e inejecutable (Güitrón, 2015). Por lo que se refiere a la regulación de esta institución o de otras parecidas en nuestro derecho, en los códigos civiles y códigos de lo familiar de los Estados de la República, se ha legislado en sendos capítulos con disímbolas características.

\section{DISCUSIÓN}

El Patrimonio Familiar es el conjunto de bienes constituido por resolución judicial y en forma única que aseguran y garantizan la subsistencia y bienestar de la familia (Baqueiro, 2014). Es una institución jurídica que fue creada para la protección de la familia (De la Fuente, 2012) afianzando el fortalecimiento de la misma con bienes que apuestan a la subsistencia familiar, pero que deberán constituir una garantía para cubrir las necesidades de habitación y bienestar, brindándole abrigo en los sobresaltos e incertidumbres económicas y con ello se posibilite el desempeño del importante papel de la solidez y fortaleza necesaria para el desarrollo de la unidad familiar, puesto que ésta es considerada la célula primordial y básica de la sociedad.

- El Patrimonio Familiar y alimentos y su obligación de darlos. La figura del Patrimonio Familiar está íntimamente ligada a la subsistencia de la familia y a la obligación de proveer alimentos; se haya íntimamente ligada con la obligación alimenticia que está a cargo de los miembros de la familia, puede llevarse a cabo por cualquiera de los miembros del grupo familiar, mayor de edad, y no necesariamente por el jefe de familia, que tenga la obligación de dar alimentos a los parientes en cuyo favor se constituye el Patrimonio Familiar, pero como la obligación alimenticia recae primeramente en los parientes más próximos en grado quienes excluyen a los más lejanos deberá entenderse de que la constitución del Patrimonio Familiar solo podrá ser autorizada para que se constituya con bienes del pariente en quien recae la obligación alimenticia, por no encontrarse en posibilidad de cumplir con ella otros parientes más próximos en grado; por lo que es importante que se tenga presente cuando existe la obligación de dar alimentos. Al respecto hay que tomar en consideración estos precios generales:

1. La obligación de dar alimentos es recíproca. El que los da tiene a su vez el derecho de pedirlos y

2. Que los cónyuges deben darse alimentos (la Ley determinará cuándo queda subsistente esta 
obligación en los casos de divorcio y otros que la misma ley señale).

- Su administración. Definido en ambos cónyuges o uno de ellos, en caso de que uno falte o se encuentre impedido o el que lo hace constituir para sus hijos, en su defecto puede ser el tutor. En caso de descendientes, colaterales, corresponde al tutor. Cuando la madre o el padre que queda en el patrimonio familiar desea contraer enlace con otra persona, debe hacer de manifiesto al juez, quien procede a mantenerlo en la misma situación, substituirlo, o designar un tutor acorde al interés de los hijos. En caso de que alguno de ellos, no de parte al juez pierde el patrimonio familiar, quedando suspendido en el ejercicio de su autoridad.

- Su objeto. Puede resultar dañado el inmueble rural o urbano, quedando anulado el instituirse más de un bien. En caso de que uno resulte, propietario de más de dos bienes de familia, procediendo a elegir uno en el plazo. En el caso de ser afectados el inmueble rural o urbano no debe exceder las necesidades y vivienda del propietario, lo anterior recae en dos condicionales: el primero acontece cuando el inmueble es del constituyente o su familia, es sin límite en relación al valor del inmueble cuando en el inmueble no habitan el constituyente ni su familia.

Requisitos para la constitución.

a. Propiedad del bien

El constituyente debe ser titular del dominio del inmueble y capaz para disponer a título oneroso. En el carácter de persona casada, debe tener el consentimiento del cónyuge en caso de inmueble ganancial o bien propio (hogar conyugal) con hijo(s) menores o incapaces, así en caso de estar disuelta la sociedad conyugal.

b. Habitación del bien

Debe de estar habitado por el propietario o beneficiario.

c. Determinación de beneficiario

El constituyente debe determinar los beneficiarios, justificando la existencia y composición de su familia. Sin existir límite en cantidad de miembros de la familia. Cuando se presentan simultáneamente cónyuge, descendientes y ascendientes, el constituyente tiene amplia facultad para elegir a los beneficiarios.

- Forma de constitución. Puede consumarse por acto jurídico en estado vivo o de última voluntad. El primero refiere la inscripción del patrimonio familiar se establece ante autoridad administrativa establecida por el Ejecutivo. Este organismo es normalmente el Registro Público de la Propiedad.

- Efectos de la constitución. Llega a producir efectos a partir de su inscripción, la cual subsiste hasta que se origine la desafectación. Dichos efectos son:

a. Inembargabilidad: Una vez afectado como bien del Patrimonio Familiar, tanto el inmueble como el Patrimonio Familiar mismo que no puede resultar ser embargado por créditos originados posterior a la inscripción en el Registro Público de la Propiedad. Excepciones previstas por la ley: créditos de tasas e impuestos gravables al inmueble, crédito de gravamen con consentimiento del cónyuge o autorización judicial. 
a. Inenajenabilidad: El inmueble afectado al régimen del Patrimonio Familiar, es inalienable, por acto entre vivos o de última voluntad. El bien no puede ser enajenado ni objeto de legados o mejoras testamentarias. Por lo que se comprende que no puede ser objeto de venta, dado en pago, permuta, donación.

b. Imprescriptibilidad: El dominio del inmueble afectado, en primicia, no puede ser adquirido por un tercero a través de la prescripción.

- Desafectación. Acto con el cual se cancela la inscripción del inmueble como Patrimonio Familiar en el Registro Público de la Propiedad. En algunas de las siguientes causales:

\section{a. Desafectación voluntarias}

Voluntad del constituyente, es decir, del propietario con la conformidad de su cónyuge. En caso de que el constituyente no es casado o el cónyuge es incapaz, valida con la limitante que el interés familiar no sea comprometido.

En mayoría de herederos, el Patrimonio Familiar este constituido por testamento, a excepción que exista discrepancia por parte del cónyuge supérstite o herederos con incapacidad A solicitud de la mayoría de los herederos, cuando el Patrimonio Familiar se hubiera constituido por disposición testamentaria, salvo que medie disconformidad del cónyuge supérstite o existan herederos incapaces, caso en el cual el juez de la sucesión o la autoridad competente resolverá lo que estime más conveniente para el interés familiar. A requerimiento de la mayoría de los condóminos, si hubiere condominio, computado en proporción a sus respectivas partes.

a. Causales forzosas de desafectación. De oficio, a instancia de cualquier interesado, cuando no permanecieren los requisitos previstos en la ley o hubieran fallecido todos los beneficiarios. En expropiación, reivindicación, venta judicial o existencia de causa grave que justifique la desafectación a juicio de la autoridad competente. El deceso del propietario no produce la desafectación del inmueble al régimen, sino que ha de seguirse un procedimiento determinado por la ley para ello.

\section{REFERENCIAS}

1. Armijo Reyes, Andrea Margarita (2016). Economía familiar y gestión del patrimoniofamiliar por las mujeres santiaguinas (Chile), 1580-1650. HiSTOReLo.Revista de Historia Regional y Local, 8(16), 14-51.

2. Baqueiro Rojas, Edgar. (2014). Derecho de familia. México: Oxford.

3. De Castro y Bravo, Federico. (2008). Derecho Civil de España. España: Civitas.

4. De la Fuente Linares, José Candido Francisco Javier. (2012). La protección constitucional de la familia en América Latina. Revista IUS, 6(29), 60-76.

5. Diario Oficial de la Federación. (1917). Constitución Política de los Estados UnidosMexicanos.

6. Borja, Durán. (2013). Gestión del patrimonio familiar. España: LID Editorial.

7. Galván Rivera, Flavio. (1996). El patrimonio familiar en el vigente derecho mexicano.México: IIJ-UNAM.

8. Güitrón Fuentevilla, Julián. (2015). La vivienda y el patrimonio familiar en México.Actualidad Jurídica Iberoamericana, núm. 3 bis, 247-266.

9. Gutiérrez y González, Ernesto. (1999). El patrimonio. México: Porrúa. 
10. Instituto de Investigaciones de Jurídicas de la Universidad Autónoma de México.(2001). Diccionario Jurídico Mexicano. México: Porrúa.

11. Rojina Villegas, Rafael. (2004). Compendio de derecho civil. México: Porrúa.

12. Lepin Molina, Cristian. (2014). Los nuevos principios del derecho defamilia. Revista chilena de derecho privado, (23), 9-55.https://dx.doi.org/10.4067/S0718-80722014000200001

13. Machado López, Libertad, Cedeño Floril, Mariuxi Paola, \& Fuentes Machado, CésarManuel. (2019). Mínima intervención del estado en los asuntos familiarescomo principio del derecho de familia. Revista Universidad y Sociedad, 11(1),148-156. 